\title{
The Occipital and Sacral Pressures Experienced by Healthy Volunteers Under Spinal Immobilization: A Trial of Three Surfaces
}

\author{
Ruairí de Fréin \\ Technological University Dublin, ruairi.defrein@tudublin.ie \\ Fintan Sheerin \\ Trinity College Dublin, Ireland
}

Follow this and additional works at: https://arrow.tudublin.ie/engscheleart2

Part of the Biomedical and Dental Materials Commons

\section{Recommended Citation \\ de Fréin, R. \& Sheerin, F. (2007)The Occipital and Sacral Pressures Experienced by Healthy Volunteers Under Spinal Immobilization: A Trial of Three Surfaces, JOURNAL OF EMERGENCY NURSING, Volume: 33,Issue: Pages: 447-450, DOI: 10.1016/j.jen.2006.11.004}

This Article is brought to you for free and open access by the School of Electrical and Electronic Engineering at ARROW@TU Dublin. It has been accepted for inclusion in Articles by an authorized administrator of ARROW@TU Dublin. For more information, please contact arrow.admin@tudublin.ie, aisling.coyne@tudublin.ie, gerard.connolly@tudublin.ie.

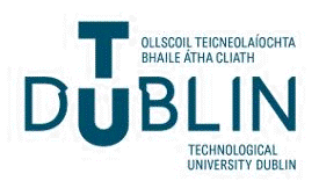




\section{The Occipital and Sacral Pressures}

\section{Experienced by Healthy Volunteers Under Spinal Immobilization: A Trial of Three Surfaces}

Authors: Fintan Sheerin, BNS, PgDipEd, PhD, RN, and Ruairi de Frein, BEng, Dublin, Ireland

Fintan Sheerin is Lecturer, School of Nursing and Midwifery Studies, University of Dublin, Trinity College, Dublin 2, Ireland.

Ruairi de Frein is Research Student, Faculty of Engineering, University College Dublin, Dublin, Ireland.

For correspondence, write: Dr. Fintan Sheerin, School of Nursing and Midwifery Studies, University of Dublin, Trinity College, Dublin 2, Ireland; E-mail: sheerinf@tcd.ie.

J Emerg Nurs 2007;33:447-50.

0099-1767/\$32.00

Copyright (C) 2007 by the Emergency Nurses Association.

doi: 10.1016/j.jen.2006.11.004
Background: The development of a pressure ulcer is of great significance to the life-long rehabilitative management of the person with a spinal cord injury, and may indeed delay and repeatedly interfere with that process. That the period preceding admission to the specialized spinal injury unit is crucial with regard to pressure ulcer development is evident in the professional literature. Both anecdotal and empirical evidence indicates that a significant number of pressure ulcers occur as a result of management provided prior to admission, and that such ulcers are more likely to occur in those patients who have undergone a transfer process from a hospital distal to the specialist unit on a hard spinal board.

Aim: In consideration of this and of the fact that, in Ireland, the interhospital transfer of spinal injured patients has usually involved the employment of such spinal boards to achieve immobilization, this study sought to identify whether or not the pressure experienced by individuals at two anatomical locations was dependent on the support surface employed.

Methodology: Pressure under the occiput and sacrum of three healthy volunteers immobilized on three support surfaces was measured using air-filled pressure-measuring sacks. The surfaces employed were an uncovered spinal board; a spinal board with inflatable raft devise; and a full-body vacuum splint.

Discussion: Marked reductions in pressure were measured when using the inflatable raft and the vacuum mattress. The results of this study will provide a basis for a larger study and, through that, the formulation of recommendations for standardized practice along a national care pathway. 
T he ongoing international debate regarding the management of how spinal cord injured patients has, during the past 10 years, been reflected in the Irish health care system by a move from the formerly conservative approach to the current surgical one. Thus, whereas patients with spinal cord injuries were previously admitted directly into rehabilitative care with a protracted period of flat bed rest, they now are transferred to an acute care facility where they are nursed on Stryker beds, stabilized, orthopedically fixed, and then referred for formal rehabilitation. Medical considerations aside, this change in service approach has had little effect on the secondary complications that plague patients with spinal cord injuries and threaten the potential for a smooth rehabilitative period. Primary among these complications is the development of pressure ulcers.

\section{Importance of Pressure Ulcers}

Pressure ulcer development in patients with spinal cord injuries is a problem of great significance; it is estimated that pressure ulcers will develop in up to $40 \%$ of patients in the immediate postinjury period ${ }^{1}$ and in up to $80 \%$ of patients overall. ${ }^{2}$ The first Irish study in this regard reported an incidence of $37 \%{ }^{3}$ It is further estimated that this complication carries with it a mortality rate of $7 \%$ to $8 \%{ }^{2}$

The period preceding admission to the specialist facility is recognized to be a crucial one in the prevention of pressure ulcers. ${ }^{4-6}$ This recognition has led to the development of trauma care pathways in many countries that have facilitated the speedy transfer of patients to such specialized facilities. This process has not, however, been instigated in Ireland, where the incidence of spinal injury is estimated to be at a level comparable to that of the United States and the United Kingdom. ${ }^{2}$

With significant potential existing for the development of pressure ulcers prior to the arrival of patients with spinal injuries at the acute unit, one must focus on techniques for preventing and minimizing their occurrence. The principal, preventable issue is unrelieved pressure resulting from prolonged use of spinal boards and of hard cervical collars, and it is associated with the most commonly occurring pressure ulcers - sacral, heels, occiput, ${ }^{4,7-9}$ and chin. ${ }^{10}$ The obvious answer to unrelieved pressure is to relieve the pressure.

\section{Goals of this Investigation}

The aim of this study was to examine the pressure experienced at the occipital and sacrum regions when healthy volunteers were immobilized on each of 3 spinal support surfaces. More specifically, the goals were to identify the pressures experienced at the skin over the occipital and sacral regions when placed sequentially on each of 3 spinal support surfaces.

\section{Methods}

\section{STUDY DESIGN AND SETTING}

This study was a nonrandomized control trial of spinal immobilization on 3 spinal support surfaces using a convenience sample of 2 volunteers to assess the differences in occipital and sacral tissue interface pressure. The study was carried out in the rehabilitation research laboratory of an Irish third-level institution.

\section{SELECTION OF PARTICIPANTS}

Decisions regarding the criteria for inclusion in the population were made following consideration of the professional literature. The principal criterion was that subjects must have no history of back or neck pain/disease. For the purpose of this pilot study, it was agreed that a convenience sample, comprising 2 healthy volunteers, would be recruited from within the research team.

\section{INTERVENTIONS}

During the initial testing of the pressure monitoring equipment, it had been noted that the presence of clothing over the sacrum resulted in inaccurate readings. It was therefore decided that subjects would be attired in hospital gowns, with the pressure sensors placed in contact with the skin.

Subjects were fitted with a rigid cervical collar and then were sequentially placed on (1) an unpadded long spinal board with head immobilizer and spider strapping; (2) a long spinal board with inflatable raft device, head immobilizer and spider strapping; and (3) a full-body vacuum splint.

These procedures were performed by a Health Service Executive (Eastern Area) EMT according to the Pre-Hospital Emergency Care Council standard guidelines, thus maximizing the potential for consistency in spinal immobilization. 


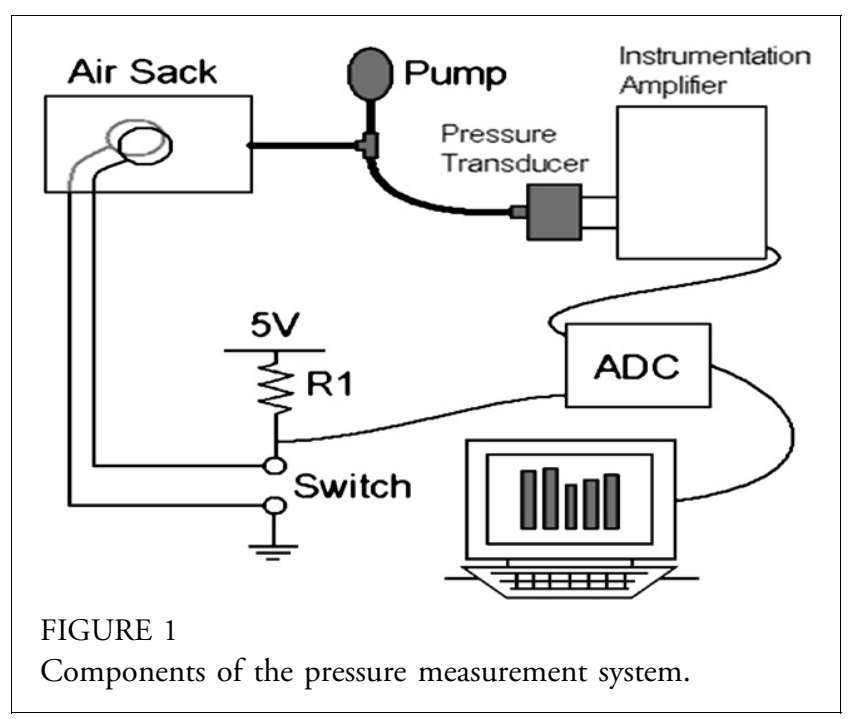

\section{METHODS OF MEASUREMENT AND DATA COLLECTION}

The pressure at each point was measured using an air-filled pressure measurement sack. This sack was formed from 2 small rectangles of thin rubber, each of which had a small metal contact at its center, to which an insulated electrical lead was connected. One rectangle was placed on top of the other with the metal contacts touching. A rubber adhesive applied around the edges of the rectangles formed an airtight seal between the two, except at a single point where an air tube connected the inside and outside of the sack to allow inflation (Figure 1).

During pressure measurement, the sacks initially were deflated. The metal contacts were touching, as a result of which the 2 wires leading from the sacks were short circuited. The sacks were placed on the sacrum (superior to the anal crease) and occiput (superior to the upper rim of the cervical collar) of the subject's body. The sacks were maintained in position by the use of tubular gauze. The sacks were inflated using a hand pump until an open circuit between the 2 wires was sensed, which indicated that the contacts had separated, and consequently that the air pressure within the sack was equal to that applied to its outer surface. Also connected to the hand pump was a SenSym SX Series gas pressure transducer that converted the air pressure within the sack into an analogue voltage. The computer was equipped with a PicoTech ADC11 analogue-to-digital converter (ADC), which monitored both the output voltage of the pressure transducer (via an

\begin{tabular}{|c|c|c|c|c|}
\hline \multicolumn{5}{|c|}{$\begin{array}{l}\text { TABLE } 1 \\
\text { Body characteristics for each participant }(n=2)\end{array}$} \\
\hline Age $(y)$ & Sex & Weight (kg) & Height (m) & Body mass index \\
\hline 41 & Male & 82 & 1.68 & 29.05 \\
\hline 23 & Male & 67 & 1.77 & 21.39 \\
\hline
\end{tabular}

instrumentation amplifier) and the state (either open circuit or short circuit) of each of the sacks. The air pressure at the moment of separation of the contacts in a given sack was recorded by the computer as the pressure on the skin at the location of that sack on the subject's body.

Special software was developed to record and display the pressure readings from each of the 2 sacks. During inflation, the pressure reading displayed for each sack varied in real time. At the moment of contact separation for a given sack, the pressure reading for that sack froze and an audible alarm sounded to inform the user that she or he could move on to inflation of the next sack.

\section{OUTCOME MEASURES}

The main outcome measure was the reduction of pressure experienced at the occipital and sacral regions as recorded by the pressure pads. Secondary outcome measures included the usability of the pressure monitoring system for employment in further studies.

\section{PRIMARY DATA ANALYSIS}

Because the sample size was very small and it was not possible to perform meaningful inferential statistics, only descriptive analyses are used to record results.

\section{Results}

Two conveniently sampled volunteers were enrolled in the study. Their body characteristics are summarized in Table 1 .

The pressures measured at the occipital region of subject 1 were found to be considerably higher when the unpadded spinal board was used $(95 \mathrm{mmHg})$ than when the spinal board with flotation device $(66.67 \mathrm{mmHg})$ or vacuum mattress $(65 \mathrm{mmHg})$ were used. Similar findings were seen in subject 2 (spinal board, $79.5 \mathrm{mmHg}$; spinal board and flotation device, $56.67 \mathrm{mmHg}$; vacuum mattress, $54 \mathrm{mmHg}$ ) (Figure 2). At the occipital region, therefore, the lowest pressures were registered when the vacuum 


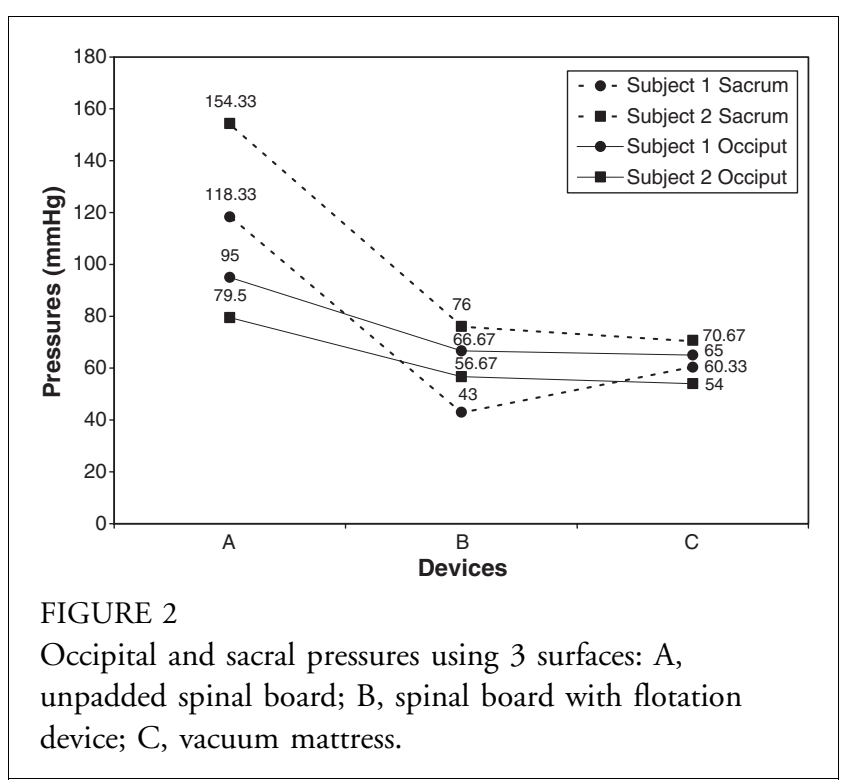

mattress was used. However, these pressures were not very different from those registered using the flotation device.

Pressures measured at the sacral region of subject 1 were found to be considerably higher when the unpadded spinal board was used $(154.33 \mathrm{mmHg})$ than when the spinal board with flotation device $(76 \mathrm{mmHg})$ or vacuum mattress $(70.67 \mathrm{mmHg}$ ) were used. Again, a similar picture was seen in subject 2 (spinal board, $118.33 \mathrm{mmHg}$; spinal board and flotation device, $43 \mathrm{mmHg}$; vacuum mattress, $60.33 \mathrm{mmHg}$ ) (Figure 2). At the sacral region, both the flotation device and vacuum mattress were associated with large reductions in pressure, with the former device resulting in a very marked reduction, in subject 2 , from that registered using the vacuum mattress.

\section{Limitations}

The main limitation with this study related to the nonrandomized character of the subjects. The main rationale for the study was to determine any change in pressure at the sacral and occipital regions of healthy volunteers when placed sequentially on 3 surfaces and to assess the usability of the pressure-measuring equipment. Both of these goals were realized. Because there was no intention to establish generalizable results at this stage, the limitations are not significant and will be eradicated when a further randomized control trial is conducted.

\section{Discussion}

It would be inappropriate to make any further comment on the aforementioned findings. This pilot study is fraught with limitations with regard to the sampling process and the small number of subjects. The difficulty in ensuring consistent placement of pressure sensors and the large size of such sensors also are issues that limit the generalizability and rigor of the study. That pressure reduction was achieved by the use of the flotation device and vacuum mattress was demonstrated in 2 subjects. On this basis, it is recommended that a full study with a sample that is more representative of the population be carried out. For such a study to be successful, modifications would need to be made to the pressure sensors to allow their adherence to the subject's skin and to ensure consistency in placement. These modifications also would permit the use of statistical analyses to examine the significance of pressure differences. If these findings are confirmed by further research, this will have implications for emergency nurses' management of patients with spinal cord injuries in the immediate prespecialist unit stage of care.

\section{REFERENCES}

1. Mawson A, Biundo J, Neville P. Risk factors for early development of pressure ulcers following spinal cord injury. Am J Phys Med Rehabil 1988;67:123-7.

2. Byrne DW, Salzberg CA. Major risk factors for the spinal cord disabled: a literature review. Spinal Cord 1996;34:255-63.

3. Sheerin F, Gillick A, Doyle B. Pressure ulcers and spinal cord injury: incidence among admissions to the Irish national specialist unit. J Wound Care 2004;14:1-4.

4. Ash D. An exploration of the occurrence of pressure ulcers in a British spinal injuries unit. J Clin Nurs 2002;11:470-8.

5. Pires M, Adkins R. Pressure ulcers and spinal cord injury: scope of the problem. Top Spinal Cord Inj Rehabil 1996;2:1-8.

6. Lovell M, Evans J. A comparison of the spinal board and the vacuum stretcher, spinal stability and interface pressure. Injury 1994;25:179-80.

7. Chen D, Apple D, Hudson L, Bode R. Medical complications during acute rehabilitation following spinal cord injury-current experience of the Model Systems. Arch Phys Med Rehabil 1999; 80:1397-401.

8. McKinley WO, Jackson AB, Cardenas DD, DeVivo MJ. Longterm medical complications after traumatic spinal cord injury: a regional model systems analysis. Arch Phys Med Rehabil 1999; 80:1402-10

9. Watts D, Abrahams E, MacMillan C, Silver R, VanGorder S, Waller $\mathrm{M}$, et al. Insult after injury: pressure ulcers in trauma patients. Orthopaedic Nurs 1998;17:84-91.

10. Blaylock B. Solving the problem of pressure ulcers resulting from cervical collars. Ostomy Wound Manage 1996;42:26-33. 